\title{
Electron Impact Mass Spectroscopic Studies on Mouse Retinal Fatty Acids
}

\section{Effect of Diabetes}

\author{
K.R. Hegde ${ }^{a}$ S.D. Varma ${ }^{a, b}$ \\ Departments of ${ }^{\mathrm{a}}$ Ophthalmology and Visual Sciences, and ${ }^{\mathrm{b}}$ Biochemistry and Molecular Biology, University of \\ Maryland School of Medicine, Baltimore, Md., USA
}

\section{Key Words}

Fatty acids · Diabetic retina $\cdot$ Gas chromatography-mass spectrometry of fatty acids

\begin{abstract}
Aim: The primary objective of these investigations was to determine the fatty acid composition of the mouse retina as affected by diabetes. Additionally, in order to ascertain if there is any accumulation of lipids in the diabetic retina as occurs in many diabetic tissues, its total fatty acid content was also determined. Methods: Lipids in the retina of normal and diabetic mice were trans-methylated with methanolic $\mathrm{HCl}$. The esters so prepared were analyzed for fatty acids by gas chromatography-mass spectrometry, qualitatively as well as quantitatively. Results: The major fatty acids in the retina were palmitic $(P A)$, oleic $(O A)$, stearic $(S A)$, arachidonic (AA) and docosahexaenoic (DHA) acids. The content of all these fatty acids increased significantly in the diabetic retina, reflecting lipidosis. The major increases $(\sim 3$ times the normal) were found in PA, OA, SA and AA. The increase in $\mathrm{DHA}$, however, was much less ( $\sim 1.4$ times). The relative percentages of fatty acids were also affected. While the relative percentages of PA and OA increased in the diabetic retina, there were insignificant changes in the percentages of SA and AA. Interestingly, the relative percentage of DHA underwent a significant decrease, about $50 \%$ of the normal. Conclusions: The results show that there is excessive accumulation of lipids in the diabetic retina. This is consistent with the
\end{abstract}

known increased mobilization of lipids from the adipose tissue and their accumulation in other tissues under diabetic conditions. On a percentage profile basis, while the relative percentage of most of the fatty acids increased, the DHA percentage significantly decreased. This could be explained by its dilution by the fatty acids coming from the fat depots which lack DHA. Physiologically, the excessive accumulation of fatty acids in the diabetic retina correlates with the lipofuscinosis and neural dysfunction associated with this disease.

Copyright $\odot 2009$ S. Karger AG, Basel

\section{Introduction}

Diabetic retinopathy is a highly prevalent vision-impairing disease. Treatment options are limited and beset with only partial success. Clinically, the disease is detected by abnormal microvascular manifestations, such as the formation of microaneurysms, dot and blot hemorrhages and tissue edema, all with adverse effects on vision. The above pathophysiological aberrations become functionally more significant when they occur in the macula. Although the above changes are the standard clinical hallmarks of the disease, it is highly likely that the initial degenerative changes start in the neural tissue even before the disease is diagnosed clinically on the basis of vascular changes. Several functional defects in the retina, such as the impairment of color vision, contrast

\section{KARGER}

(C) 2009 S. Karger AG, Basel

Fax +41613061234 E-Mail karger@karger.ch www.karger.com www.karger.com/ore
Prof. Shambhu D. Varma, PhD

Department of Ophthalmology and Visual Sciences

University of Maryland School of Medicine

MSTF 5-00A, 10 South Pine Street, Baltimore, MD 21201 (USA)

Tel. +1 410706 3395, Fax +1 410706 7057, E-Mail svarm001@umaryland.edu 
sensitivity, cone adaptation and electrophysiological dysfunction reflected by abnormalities in the electroretinogram, are well known to manifest in diabetic patients even prior to the appearance of visible vasculopathy [1].

Unlike those in type I diabetes, the manifestations in type II represent an acceleration of the normal aging processes - milder retinal changes occurring even in the latter group belatedly because of the ongoing oxidative stress, a common phenomenon implicated in many other aging deteriorations. It is generally accepted that the magnitude of oxidative stress is significantly enhanced in diabetes due to excessive generation of reactive oxygen species (ROS) [2-4]. This is due to the inhibition of glucose metabolism, diverting the available oxygen to the monovalent pathways of oxygen reduction generating superoxide and its derivatization to other potent oxidants such as hydrogen peroxide and hydroxyl radical. That there is an increase in the availability of unused oxygen in diabetes is apparent directly in the decreased respiratory quotient as first determined by Richardson [5] and Richardson and Levine [6]. The enhancement of ROS formation in diabetes is also attributable to glycation and consequent inactivation of many enzymes involved in tissue metabolism, in addition to deterioration of the structural proteins and transporters subsequent to glycation $[7,8]$. The decrease in metabolic utilization of oxygen also makes it available to trigger auto-oxidative reactions and aberrations in the ratios of redox couples such as GSH/GSSG as previously reported [9-11]. Although oxidative stress is highly likely to be involved in the genesis of many eye diseases such as cataracts [10], the retina seems to be biochemically more susceptible to oxidative injury. One of the most significant biochemical differences between the retina and other ocular tissues is the abundance of highly unsaturated fatty acids such as arachidonic and docosahexaenoic acid (DHA) in this tissue, particularly in the photoreceptors $[12,13]$. The presence of such polyunsaturated residues makes them highly susceptible to oxidative degradation, especially in diabetes, where ROS generation is greatly amplified. Initial oxidation of these fatty acids induces cis-trans modifications affecting the membrane structure. Subsequently, they undergo further degradation, generating toxic products such as malonaldehyde, a potent cross-linking dialdehyde. It is anticipated that such modifications and degradations will be highly detrimental to tissue structure and physiology, perhaps providing a fertile ground in the neural retina for initiation of vascular changes. The loss of DHA can also impair photoreceptor disk regeneration and function and synaptic transmission [14-16]. In addi- tion, oxidative loss of these polyunsaturated fatty acids can also have an adverse effect on its neuroprotective functions [17]. In addition to structural changes caused by oxidative modifications in the elements of the visual pathway, other metabolic changes innate to diabetes such as the inhibition of carbohydrate metabolism and associated lipidosis can also induce toxic reactions. We have recently reported the induction of lipid peroxidation in the retina exposed to ROS and its prevention by pyruvate [18], providing more definitive evidence of the susceptibility of the retinal lipids to peroxidative degradation.

The objectives of these investigations were hence to study possible elevation of the fatty acid content in diabetes and to determine any possible modification of the fatty acid profile expressed as the percentages of the total fatty acids. Such studies are highly lacking at present. There is only one study by Futterman et al. [19], who observed that the relative percentage distribution of DHA in the retina of alloxan-diabetic rats decreased by about $30 \%$ as compared to the normal. However, the identification of the fatty acids could be done only on the basis of the retention time of the esters on gas chromatography (GC). Lipidosis assessment was also not done. Assessment of changes in the fatty acid components of the retina in diabetes in the present study was done using the diabetic mouse model using GC coupled to electron impact quadrupole mass spectrometer, a technique more precise and definitive for fatty acid identification. The use of this animal model was also considered essential in view of the genomic similarity of the mouse with humans, as recently established, and also because of the continued development of transgenics and knockouts in this species.

\section{Materials and Methods}

CD-1 albino mice weighing $\sim 25 \mathrm{~g}$, obtained from Charles River Laboratories (Wilmington, Mass., USA), were used in these experiments. The animals were maintained on a standard laboratory diet (2018SX, Harlan Teklad). Diabetes was induced by intraperitoneal injection of streptozotocin (STZ, $40 \mathrm{mg} / \mathrm{kg}$ body weight/ day) for 6 consecutive days. Establishment of hyperglycemia was verified by determining blood glucose level after 1 week of the last injection of STZ. Glucose was determined enzymatically in the tail blood, using glucometer (Lifescan, Milpitas, Calif., USA). The levels were also determined subsequently at monthly intervals. The blood sugar varied between 350 and $450 \mathrm{mg} / \mathrm{dl}$. Ketonemia was mild, urinary ketones being $\sim 5 \mathrm{mg} / \mathrm{dl}$. Animals were not treated with insulin at any time. Mortality was not more than $10 \%$. Additional animal details have been described in our previous publication [20]. The animals were euthanized by $\mathrm{CO}_{2}$ inhalation and then the retina isolated through a corneal incision. Each retina was lyophilized, weighed and transferred into a Pyrex tube, mixed 


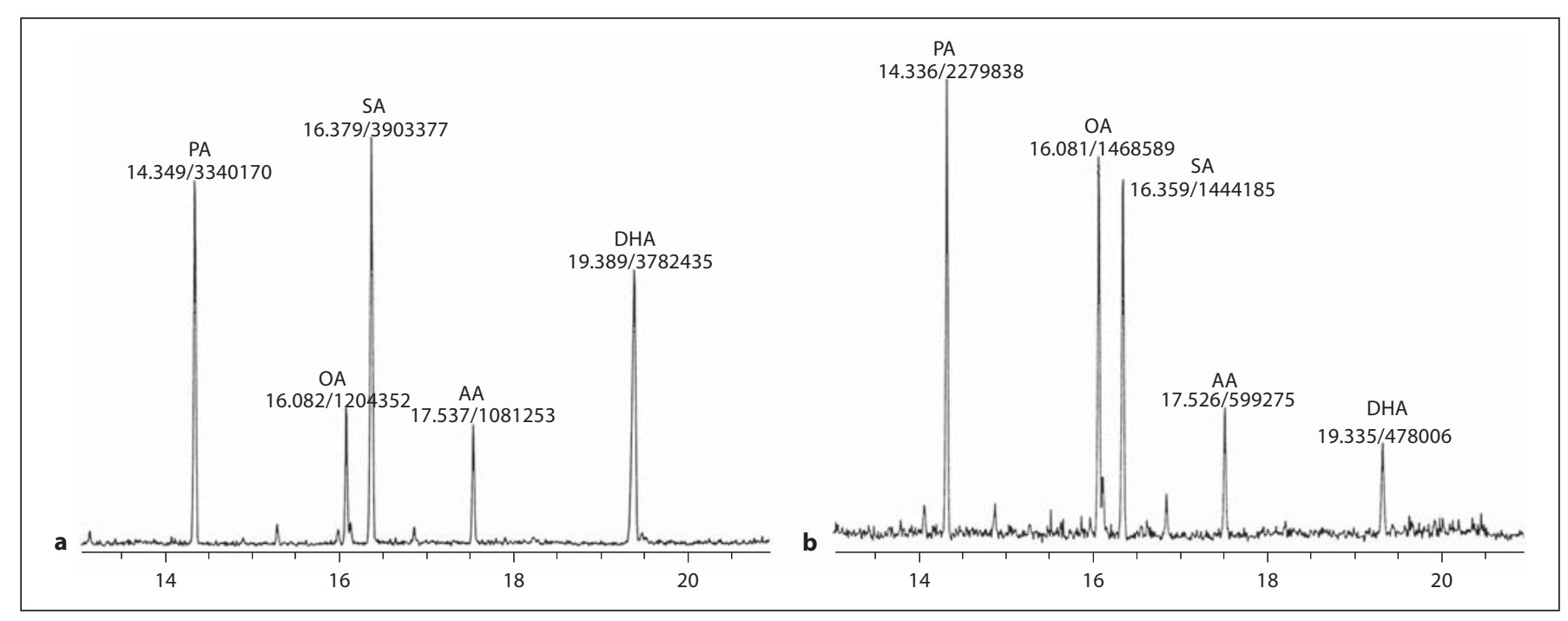

Fig. 1. Representative chromatograms of retinal fatty acids in normal (a) and diabetic (b) mice. Peaks were identified on the basis of their retention time as well as their mass spectra, with reference to the corresponding standards. The amount of fatty acid present in each peak, represented by the peak area, was calculated on the basis of peak areas obtained by injecting known amounts of standards.

with $0.3 \mathrm{ml}$ methanolic $\mathrm{HCl}$ (3 N, catalogue No. 3-3355; Supelco, Bellefonte, Pa., USA) and trans-methylation done by heating the tubes in a water bath at $80^{\circ} \mathrm{C}$ for $30 \mathrm{~min}$ [21]. The tubes were then cooled and their contents mixed again by homogenization. The tubes were then heated further for another $30 \mathrm{~min}$. After cooling, the contents were mixed with $0.3 \mathrm{ml}$ of $\mathrm{dH}_{2} \mathrm{O}$. The methyl esters present in the mixture were then extracted by shaking with $0.6 \mathrm{ml}$ low-boiling point $\left(40-60^{\circ} \mathrm{C}\right)$ petroleum ether followed by centrifugation. The upper phase containing the methyl esters was aspirated and transferred to a separate tube. The lower phase was reextracted with petroleum ether 2 times. Any moisture in the extract collected was removed by addition of a few crystals of anhydrous sodium sulfate in the tube and leaving it for some time. The contents were then centrifuged to bottom out the sodium sulfate crystals. The dehydrated extract was transferred to a vial with a Teflon-lined cap, evaporated under nitrogen and lyophilized. The residue was then dissolved in n-hexane and subjected to GCmass spectrometry using GC-17A coupled to mass spectrometer QP-5000 (Shimadzu, Kyoto, Japan), fixed with an SE-54 capillary column of $30 \mathrm{~m}$ length and $0.32 \mathrm{~mm}$ internal diameter (catalogue No. 19646; Alltech, Deerfield, Ill., USA). The column temperature was programmed as follows: the initial temperature was set at $60^{\circ} \mathrm{C}$ for $1 \mathrm{~min}$, increasing to $120^{\circ} \mathrm{C}$ by $4 \mathrm{~min}$ at the rate of $20^{\circ} \mathrm{C} /$ min, followed by an increase at the rate of $10^{\circ} \mathrm{C} / \mathrm{min}$ to attain $260^{\circ} \mathrm{C}$ by $18 \mathrm{~min}$ and remaining constant at $260^{\circ} \mathrm{C}$ till $21 \mathrm{~min}$. The split ratio was 10 . Standard mixtures of fatty acid methyl esters (catalogue No. 1892, D2659 and A9298; Supelco) containing known amounts of esters were simultaneously run. Quantitation of the esters in the extract was done by reference to the peak areas of the standards represented electronically. Identification of the peaks was done by reference to the retention time as well as mass spectra obtained from the standards and the sample.

GC-Mass Spectrometry of Retinal Fatty

Acids of Normal and Diabetic Mice

\section{Results}

Figure la describes the electron impact chromatogram representing esters present in a representative normal retinal sample trans-esterified with methanol as described above. The major peaks identified were: palmitic (16:0), oleic $\left(18: 1^{\Delta 9}\right)$, stearic (18:0), arachidonic $\left(20: 4^{\Delta 5,8,11,14}\right)$ and docosahexaenoic $\left(22: 6^{\Delta 4,7,10,13,16,19}\right)$ acids. The peaks were well separated for the purpose of identification of the fatty acids by their retention time as well as by the mass spectra. The peak heights and areas were also found to correlate quantitatively with the amount of the methyl esters injected. The fatty acid profile of the diabetic retina is represented by the peaks present in figure 1b. It is apparent that although the diabetic retina has all the fatty acids that are present in the normal retina, the fatty acid composition of the diabetic retina differs significantly from that in the normal, expressed both on the basis of the absolute amount per dry tissue weight as well as on the basis of mutual (relative) percentage of the total fatty acid resolved. These values are derived as follows. The amount of fatty acid in each peak was determined by reference to peak areas (electronic) obtained by injecting known amounts of the corresponding standard fatty acid methyl esters. The total a mount of fatty acids representing the entire chromatogram was then calculated by adding the amounts of all the indi- 


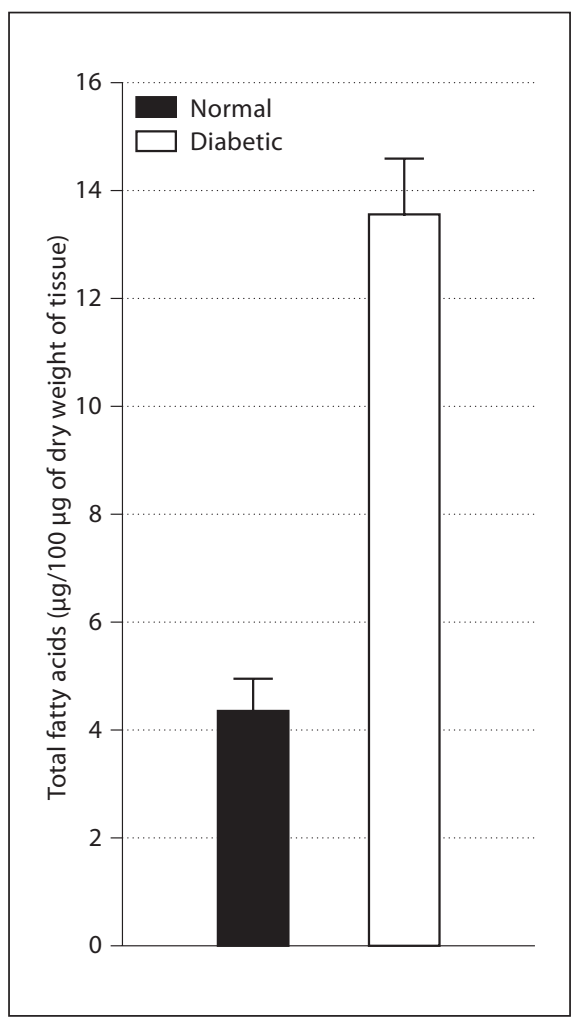

Fig. 2. Total fatty acid content of the retina. The values are expressed as mean $\pm \mathrm{SD} ; \mathrm{n}$ (number of retinas) $\geq 8$ in each group. The total amount of fatty acids was calculated by adding the amounts of the individual fatty acids and then expressing it in terms of micrograms per $100 \mu \mathrm{g}$ of dry weight of the tissue. $\mathrm{p}<$ 0.001 between the normal and diabetic groups [29].

vidual fatty acids resolved. The dry weight of the tissue was predetermined. As shown in figure 2, the total fatty acid content of the retina increased from $4.3 \mu \mathrm{g} / 100 \mu \mathrm{g}$ of the dry tissue weight in the normal to $13.5 \mu \mathrm{g} / 100 \mu \mathrm{g}$ in diabetes. This increase was reflected more significantly in the case of palmitic, oleic, stearic and arachidonic acids, being 3.7, 4, 3.4 and 3 times the normal, respectively, as shown in table 1. In the case of DHA, the level was only 1.4 times the normal. The tissue therefore has become lipidotic, as happens in many other diabetic tissues. The above increases are also apparent in terms of the relative percentages of the individual fatty acids, particularly in the case of palmitic and oleic acids. Stearic and arachidonic acid percentages did not change. Interestingly, the percentage of DHA decreased despite increase in its absolute level. The lowering of the percentage of this fatty acid is accountable to its dilution by influx of depot lipids in diabetes. The depot lipids are also deficient in their DHA content. The persistence of DHA, though helpful in maintaining neural function, obviously makes the tissue relatively more susceptible to peroxidative degradation with the generation of reactive species of oxygen. In addition, such degradation leads to the formation of malonal (MDA) and other toxic aldehydes [22, 23].

\section{Discussion}

In view of the fact that the prevalence of diabetic retinopathy is on a rise worldwide, extensive clinical, pharmacological and biochemical studies are in progress in several laboratories. However, in most of these studies, vasculopathy is the main target of investigations. Basic studies on the neural retina are relatively few, particularly with regard to its fatty acid composition [19]. One of the basic objectives of this study was hence to provide additional baseline quantitative as well as qualitative information on its status as affected by the disease. These studies have been conducted in a mouse model because of its several genomic and biochemical similarities with humans. In addition, recent epidemiological studies strongly suggest that the ocular changes including cataracts and diabetic retinopathy are susceptible to attenuation by normalizing the blood glucose levels. Unfortunately, however, the level of hyperglycemia attained in the commonly used mutant strains of $\mathrm{C}_{57} \mathrm{Bl}$ mice, $\mathrm{C}_{57} \mathrm{Bl} /$ $\mathrm{KSJ} \mathrm{db} / \mathrm{db}$ and $\mathrm{C}_{57} \mathrm{Bl} / 6 \mathrm{~J} \mathrm{ob} / \mathrm{ob}$, is relatively mild [24], which fails to produce marked pathological changes noted in human diabetic retina. In view of this, we conducted the present studies in mice rendered diabetic by STZ administration wherein the level of hyperglycemia was maintained consistently at a higher level (350-450 $\mathrm{mg} / \mathrm{dl}$ ), similar to the level in most untreated diabetics. However, maintenance of these diabetic animals for a relatively longer duration was initially difficult because of high mortality soon after the induction of diabetes with a single bolus dose of STZ. We have been able to overcome this difficulty by injecting STZ in divided doses, instead of a single dose, over a period of 6 days [25]. We are able to maintain such animals for a period of at least 6-8 months without any significant casualties and weight loss [20].

The present observations strongly suggest that there is excessive accumulation of lipids in the diabetic retina. The elevation in the retinal lipids was clearly reflected by the elevation of the contents of the individual fatty acids, the overall increase being 3 times of the normal, except in the case of DHA where the amount increased 
Table 1. Fatty acid composition of the normal and diabetic mouse retina

\begin{tabular}{|c|c|c|c|c|c|}
\hline & \multicolumn{2}{|l|}{ Normal (N) } & \multicolumn{2}{|l|}{ Diabetic (D) } & \multirow{2}{*}{$\begin{array}{l}\text { Ratio of amount } \\
\text { in diabetic vs. } \\
\text { normal }(\mathrm{D} / \mathrm{N})\end{array}$} \\
\hline & $\begin{array}{l}\text { relative } \% \text { of the } \\
\text { total fatty acids }\end{array}$ & $\begin{array}{l}\text { amount, } \mu \mathrm{g} / 100 \mu \mathrm{g} \\
\text { dry retinal weight }\end{array}$ & $\begin{array}{l}\text { relative } \% \text { of the } \\
\text { total fatty acids }\end{array}$ & $\begin{array}{l}\text { amount, } \mu \mathrm{g} / 100 \mu \mathrm{g} \\
\text { dry retinal weight }\end{array}$ & \\
\hline Palmitic acid (PA) & $31.5 \pm 2.2$ & $1.33 \pm 0.09$ & $36.5 \pm 4.9^{*}$ & $4.9 \pm 0.66^{*}$ & 3.7 \\
\hline Linolenic acid (LA) & trace & - & $5.2 \pm 0.7$ & $0.7 \pm 0.1$ & \\
\hline Oleic acid (OA) & $18.9 \pm 1.5$ & $0.81 \pm 0.06$ & $23.6 \pm 1.9^{*}$ & $3.2 \pm 0.26^{*}$ & 4 \\
\hline Stearic acid (SA) & $25.3 \pm 3.6$ & $1.1 \pm 0.15$ & $27.4 \pm 3.8$ & $3.7 \pm 0.51^{*}$ & 3.4 \\
\hline Arachidonic acid (AA) & $9.7 \pm 1.7$ & $0.4 \pm 0.07$ & $8.7 \pm 4.7$ & $1.2 \pm 0.63^{*}$ & 3 \\
\hline Docosahexaenoic acid (DHA) & $12.5 \pm 2$ & $0.62 \pm 0.3$ & $5.5 \pm 3.5^{*}$ & $0.87 \pm 0.4^{*}$ & 1.4 \\
\hline
\end{tabular}

The values represent the individual fatty acids as percentage of the total fatty acids in the chromatogram. The absolute amounts of the individual fatty acids are also shown, in terms of micrograms per $100 \mu \mathrm{g}$ dry weight of the retina. Data are expressed as mean \pm $\mathrm{SD} ; \mathrm{n}$ (number of retinas) $\geq 8$ in each case except linolenic acid which was at detectable level in only 2 chromatograms from the diabetic group. A significant difference is apparent in the percentage content of PA, OA and DHA between the normal and diabetic retina.

* The $\mathrm{p}$ values for these differences are as follows: PA and $\mathrm{OA}<0.001$ and $\mathrm{DHA}<0.001$. The differences in the absolute amounts of $\mathrm{PA}, \mathrm{OA}, \mathrm{SA}$, and AA were also very significant; $\mathrm{p}<0.001$, and 0.05 for DHA.

to about 1.4 times the normal (table 1). The exact source of the observed increase in the fatty acids in the diabetic retina is not clear at this time. However, in the other tissues this is attributed to an increased mobilization of lipids from the adipocytes to the plasma and their eventual transport to peripheral tissues [26]. In diabetes this process of mobilization is triggered by lack of insulin, which normally modulates the process. It has a suppressive effect that is antagonized by epinephrine and glucagon. In addition, there are indications that the lipid uptake by tissues is also increased in diabetes [26, 27]. The accumulation of lipids in the diabetic tissues has also been attributed to the inhibition of $\beta$-oxidation of the fatty acids [28]. Hence, lipid accumulation in the diabetic retina, noted for the first time, could be a multifactorial process deserving further studies, specially in view of the fact that lipofuscinosis is a significant pathology of the diabetic retina.

Elevation in the fatty acids when expressed on the tissue dry weight basis was also reflected by significant elevations in the percentages of palmitic and oleic acids. The percentages of stearic and arachidonic acids remained unchanged. On the contrary, DHA percentage decreased significantly. This decrease is mainly attributable to the influx of extraretinal lipids and its consequent dilution, the content of DHA in such lipids being low. The source of this acid for the retina is primarily the liver where it is synthesized de novo from the precursor fatty acids that are derived from the diet.
The physiological relevance of the lipid accumulation in the diabetic retina is not apparent at present. However, such accumulation has been known to cause deterioration of vision in many diseases such as age-related macular degeneration.

\section{Acknowledgments}

The study was supported by NIH Grant No. EY0 1292 and, Research to Prevent Blindness Inc., New York. The authors greatly appreciate the help of Dr. Alexei Gapeev in the use of GC-MS.

References

Ophthalmic Res 2009;42:9-14 $\checkmark 1$ Bresnick GH: Diabetic retinopathy viewed as a neurosensory disorder. Arch Ophthalmol 1986;104:989-990.

2 Baynes JW: Role of oxidative stress in development of complications in diabetes. Diabetes 1991;40:405-412.

3 Ceriello A, Giugliano D, Quatraro A, Dello Russo P, Lefèbvre PJ: Metabolic control may influence the increased superoxide generation in diabetic serum. Diabet Med 1991;8: 540-542.

- 4 Altomare E, Vendemiale G, Chicco D, Procacci V, Cirelli F: Increased lipid peroxidation in type 2 poorly controlled diabetic patients. Diabetes Metab 1992;18:264-271.

5 Richardson HB: The capacity to oxidize carbohydrate as determined by the respiratory quotient. Monatsschr Kinderheilkd 1925;24: 588-593. 
6 Richardson HB, Levine SZ: Clinical calorimetry. XXXIX. Exercise and the respiratory quotient in diabetes. J Biol Chem 1925; 66:161-183.

7 Monnier VM, Stevens VJ, Cerami A: Nonenzymatic glycosylation, sulphydryl oxidation and high molecular weight aggregation of lens proteins in experimental sugar cataracts. J Exp Med 1979;50:1098-1117.

$>8$ Blakytny R, Harding JJ: Glycation (non-enzymatic glycosylation) inactivates glutathione reductase. Biochem J 1992;288:303-307.

$\checkmark 9$ Wolff SP, Crabbe MJC, Thornalley PJ: The autooxidation of glyceraldehydes and other simple monosaccharides. Experientia 1984; 40:244-246.

-10 Zhao W, Devamanoharan PS, Henein M, Ali AH, Varma SD: Diabetes-induced biochemical changes in rat lens: attenuation of cataractogenesis by pyruvate. Diabetes Obes Metab 2000;2:165-174.

- 11 Kowluru RA, Kern TS, Engerman RL, Armstrong D: Abnormalities of retinal metabolism in diabetes or experimental galactosemia. III. Effects of antioxidants. Diabetes 1996;45:1233-1237.

12 Fliesler SJ, Anderson RE: Chemistry and metabolism of lipids in the vertebrate retina; in Holman RT (ed): Progress in Lipid Research. Oxford, Pergamon Press, 1983, vol 22, pp 79131.

13 Wurtman RJ, Wurtman JJ (eds): Nutrition and the Brain. New York, Raven, 1990, vol 8, pp 1-24.

14 Benolken RM, Anderson RE, Wheeler TG: Membrane fatty acids associated with the electrical response in visual excitation. Science 1973; 182:1253-1254.
15 Neuringer M, Connor WE, Lin DS, Barstad L, Luck S: Biochemical and functional effects of prenatal and postnatal omega 3 fatty acid deficiency on retina and brain in rhesus monkeys. Proc Natl Acad Sci USA 1986;83: 4021-4025.

16 Bicknell IR, Darrow R, Barsalou L, Fliesler SJ, Organisciak DT: Alterations in retinal rod outer segment fatty acids and light-damage susceptibility in $\mathrm{P} 23 \mathrm{H}$ rats. Mol Vis 2002; 8:333-408.

17 Kim HY, Akbar M, Lau A, Edsall L: Inhibition of neuronal apoptosis by docosahexaenoic acid (22:6n-3): role of phosphatidylserine in antiapoptotic effect. J Biol Chem 2000; 275:35215-35223.

18 Hegde KR, Varma SD: Prevention of oxidative stress to the retina by pyruvate: a preliminary report. Ophthalmologica 2008; 222:194-198.

$>19$ Futterman S, Sturtevant R, Kupfer C: Effect of alloxan diabetes on the fatty acid composition of the retina. Invest Ophthalmol 1969;8: 542-544.

$\checkmark 20$ Hegde KR, Henein MG, Varma SD: Establishment of the mouse as a model animal for the study of diabetic cataracts. Ophthalmic Res 2003;35:12-18.

21 Shimasaki H, Phillips FC, Privett OS: Direct transesterification of lipids in mammalian tissue for fatty acid analysis via dehydration with 2,2'-dimethoxypropane. J Lipid Res 1977; 18:540-543.
22 Hegde KR, Henein MG, Varma SD: Establishment of mouse as an animal model for study of diabetic cataracts: biochemical studies. Diabetes Obes Metab 2003;5:113119.

-23 Kowluru RA, Tang J, Kern TS: Abnormalities of retinal metabolism in diabetes and experimental galactosemia. VII. Effect of longterm administration of antioxidants on the development of retinopathy. Diabetes 2001; 50:1938-1942.

24 Peluffo RO, Ayala S, Brenner RR: Metabolism of fatty acids of the linoleic acid series in testicles of diabetic rats. Am J Physiol 1970; 218:669-673.

25 Varma SD, Kinoshita JH: Absence of cataracts in mice with congenital hyperglycemia. Exp Eye Res 1974;19:577-582.

$>26$ Like AA, Appel MC, Williams MR, Rossini A: Streptozotocin-induced pancreatic insulitis in mice. Lab Invest 1978;38:470-485.

27 Flakoll P, Carlson MG, Cherrington A: Physiologic action of insulin; in LeRoith D, Taylor SI, Olefsky JM (eds): Diabetes Mellitus: A Fundamental and Clinical Text. Philadelphia, Lippincott-Raven, 1996, pp 124-126.

28 Bonen A, Parolin ML, Steinberg GR, et al: Triacylgycerol accumulation in human obesity and type 2 diabetes is associated with increased rates of skeletal muscle fatty acid transport and increased sarcolemmal FAT/ CD36. FASEB J 2004; 18:1144-1146.

$>29$ Goodpaster BH, Wolf D: Skeletal muscle lipid accumulation in obesity, insulin resistance and type 2 diabetes. Pediatr Diabetes 2004;5:219-226.

30 Altman DG: Practical Statistics for Medical Research. London, Chapman \& Hall, 1991, pp 179-228. 